\title{
La herencia de los animales de compañia
}

Keywords: derecho; legislación; jurisprudencia; animal

Está siendo noticia estos días la herencia millonaria recibida por tres Asociaciones dedicadas a la Protección de los Animales (entre ellas, la dedicada a la conservación del lince ibérico y la Asociación de protección de los borricos de Rute. Los comentarios han oscilado entre el estupor y la ironía. Por supuesto, también se han publicado expresiones de admiración por el gesto de generosidad de una vecina de Telde, que decidió favorecer con sus bienes a los que se dedican -muchas veces con escasos medios-, a mejorar la vida de los animales o a procurar que una especie no se extinga.

La cuestión, es de gran interés y no está del todo resuelta en nuestro Derecho. En efecto, el testamento, es un acto personalísimo y libérrimo en el que el causante (Cc. art 670), con las bien conocidas restricciones de reserva legítima (Cc. art. 806ss.), puede disponer de lo suyo de la forma y modo que estime convenientes (Cc art. 667ss.). A muchas personas se les plantea la duda de cómo asegurar el bienestar de su animal de compañía, en caso de muerte o de incapacidad. La fórmula usada en la mayoría de los supuestos, es la designación de una persona o entidad, a la que se le confían unos bienes destinados al mantenimiento del animal. En el caso que hemos comentado, la causante ha dado el dinero a las Asociaciones, con la precisión de que se gaste únicamente el 5\% del rédito que el capital genere en el año, lo que, se calcula, podrían ser unos 150.000 Euros. En todo caso, la fórmula usada siempre se atiene a unas constantes: designación de una persona física o jurídica que se encargue de beneficiar al animal o animales, con el capital o los bienes que el testador destine a tal efecto. Es decir, el animal es beneficiario "indirecto" del capital que se destina a su manutención y cuidado, pues, como "cosa” que es para el Derecho (Cc.arts. 355; 465; 610), no puede recibir nada directamente por herencia.

Hasta aquí, sumariamente, lo que nuestro Derecho dice hasta el momento. Pero veamos cúal es la experiencia en otros países, tanto en el ámbito de la normativa, como en el de la experiencia social, es decir qué es lo que el sistema jurídico permite en relación a la herencia y los animales y cúales son las pautas sociales en tema de beneficiar a los animales, a través de donaciones o de herencia.

El ejemplo quizá más emblemático, lo ofrece la normativa de los Estados Unidos de América. Lo más característico es la existencia de leyes ("Pet Trust Act”), cuyas normas aseguran al animal una existencia digna en caso de muerte, o de incapacidad de su dueño. Existen actualmente 39 Estados de la Unión -desde Arkansas a Wyoming, pasando por California, Idaho, Wisconsin o South Carolina-, que fueron promulgando sus propias leyes ("Pets Trust Laws") (1), tras aprobarse en los años 90 el "UPC” (=Uniform Probate Code”), es decir las pautas legales a seguir en caso de que un Estado decidiera dar respuesta a la cuestión, de cómo asegurar la asistencia de un animal de compañía, en caso de que su dueño no pudiera hacerse cargo de él (ㄹ) .

Consiste el "Pet Trust” en un fideicomiso a favor del animal de compañía, en el que el disponente destina una cantidad de dinero o bienes y especifica la forma en que desea que se efectúen los desembolsos, a favor del animal de compañía. Para ello, se nombra a un responsable ("trustee") que debe atenerse a las previsiones que el fideicomitente especifique, relativas a alimentos, asistencia veterinaria, cuidados varios e, incluso, de una eventual eutanasia, si el animal sufriera una enfermedad grave e irreversible. Algunos dueños dejan también previsto, a qué fines se destinará el remanente del fondo, si este no se hubiera gastado durante la vida del animal al que se desea beneficiar. En la legislación de los Estados Unidos de América, el animal de compañía es directamente beneficiario del fondo que su dueño le deja para su cuidado y manutención, aunque también allí la condición jurídica de un animal sea la de "cosa en 
propiedad”. Es la estructura del fideicomiso, en el que se nombra un fideicomitente, o administrador del capital dejado en fideicomiso, lo que permite superar la imposibilidad jurídica de que el animal sea una cosa y, por tanto, sea imposible reconocerlo como sujeto de un acto jurídico, para convertirlo en el destinatario jurídicamente reconocido del “Trust”. Es interesante poner de relieve que, a día de hoy, la condición jurídica del animal como “cosa”, está siendo objeto de consideración crítica (יㅡ), cuando no de rechazo total ()ㅗ, en la doctrina americana.

Una reforma jurídica de tanto calado a favor de los animales, sin haber producido una alteración sustancial de su estatuto jurídico, es consecuencia del reconocimiento de que la mayoría de los hogares americanos (el 59\%, según estadísticas del año 2005), tienen un perro o un gato como animal de compañía y la provisión de un instrumento jurídico como el descrito, parecía -y lo es- una respuesta a la preocupación real -y exteriorizada sin miedo a la censura social-, de muchos propietarios que pueden descargar así su temor de dejar desasistido a su compañero, si les resulta imposible cuidar de él por ellos mismos. De hecho, el número de ciudadanos que actúan con tal previsión y que utilizan los servicios de un abogado para constituir un "Pet Trust", es, a día de hoy, notablemente abundante (므), lo que no hace sino revalidar la eficacia de la norma jurídica, que supo dar respuesta a una necesidad social, real y sentida en su momento, y que sigue teniendo justificación en el presente.

Por lo tocante a otros países de nuestro entorno europeo, en primer término Austria (Bundesverfassung 2004; ABGB 1986), seguida por Alemania (Bundesverfassung 2002; BGB 1990) y Suiza (Bundesverfassung 2004; BGB 2000), han reconocido en su Constitución y en sus respectivos Códigos civiles, la naturaleza de los animales como seres sensibles ("sentient beings") y, por ello, tanto en la Constitución, como en el respectivo Código civil se aparta a los animales de la clasificación de “cosas en propiedad”, que es como aparecen configurados los animales en el resto de los Códigos europeos y latinoamericanos, por influencia del Derecho Romano, donde los animales entran por primera vez en un sistema jurídico como “cosas”. Hay que mencionar aquí, como salvedad, el Código civil catalán que siguiendo el modelo de los países europeos mencionados- ya en su libro 5, promulgado en 2006, dispone que los animales "no son cosas” y se rigen por leyes especiales (므).

Este cambio de la normativa constitucional y civil no parece -al menos aparentemente- muy llamativa. Sin embargo, encierra importantes consecuencias para todo el sistema jurídico en tema de protección animal. Entre otros aspectos, podría eventualmente concretarse en los siguientes: en la posibilidad para los animales de ser beneficiarios de disposiciones testamentarias; en la instrumentación jurídica, como carga impuesta a los herederos o legatarios, de atender al animal apropiadamente; en que el "interés" del animal deberá ser tenido en cuenta en las decisiones judiciales sobre la posesión de animales de compañía, como ocurre en los casos de separaciones o divorcios; en que el valor de afección deberá ser considerado en las condenas por responsabilidad por daños causados a los animales ( $\underline{7})$.

En suma, que el Derecho y la Sociedad vayan a la par no es siempre sencillo. En los países a los que he hecho referencia en Europa, los animales de compañía son un elemento más de las familias, su integración en la vida ciudadana es un hecho ordinario e incontestable, existe un respeto generalizado por la vida animal, que se revela en los cambios legislativos que hemos detallado y en los que se siguen promoviendo como resultado de la iniciativa ciudadana (모). No obstante, en ningún Estado europeo existe la posibilidad de que un animal (aún habiéndosele declarado "no-cosa”) sea beneficiario de una disposición post mortem de su dueño, salvo en las formas que he detallado para el Derecho español. La fuerza de las “cosas”, sigue siendo, de momento,un obstáculo insalvable.

(1) Una información completa en animallaw

(2) Más ampliamente, R.HIRSCHFELD, Ensure your Pet’s future: Estate Planning for Owners and their Animal Companion, publ. en animallaw,

(3) D.FAVRE, Living Property: A new Status for Animals within the Legal System, 93 Marquette L. Rev. (2010),en prensa.

(4) G.FRANCIONE, Animals as Persons: Essays on the Abolition of Animal Exploitation (Columbia University Press 2008); también útil

una de sus primeras incursiones en el tema: Animals, Property, and the Law (Temple University Press 1995)

(5) Vid. a título de ejemplo en pettrustlawyer

(6) Codi civil de Catalunya (Llei 5/2006) Llibre 5, art. 511-1.

(7) Algunos reflejos de tales cambios pueden verse: en el BGB §251, Abs.2, sobre la obligación de pagar los gastos de curación de un animal, 
aún cuando excedan del valor del mismo, en caso de indemnización; igualmente en el ABGB § 1332 a.

(8) Proximamente (se somete a votación en Suiza, 7.3.2010, la creación de un “Abogado defensor de los animales” (Tierschutzanwalt), cuya responsabilidad sería la defensa y protección de los animales en cada cantón, como resultado de una iniciativa popular que ha contado con un fuerte apoyo. Vid. un resumen en VIMENTIS. 